\title{
Summer Shower Distribution Over the Florida Peninsula as Deduced from Digitized Radar Data
}

\author{
Neil L. Frank, Paul L. Moore and George E. Fisher ${ }^{1}$ \\ National Hurricane Center, Miami, Fla. \\ (Manuscript received 17 October 1966, in revised form 1 December 1966)
}

\section{ABSTRACT}

\begin{abstract}
Radar echoes over the Florida peninsula have been recorded manually every $3 \mathrm{hr}$ on a 7.5 by $7.5 \mathrm{mi}$ grid during the past three summers. This note summarizes the echo distribution for the period May through August 1963. The spatial and temporal variations of convective actitivy were found to be highly correlated with the sea breeze.
\end{abstract}

\section{Introduction}

The value of recording weather features observed on radar has been recognized by the Weather Bureau which has a radar-scope photography program. The researcher can often make good use of the film record. However, in many cases, the presence of echoes resulting from anomalous propagation, nearby ground clutter, or other non-meteorological targets makes it impossible

${ }^{1}$ Present affiliation: Travelers Research Center, Inc., Hartford, Conn. to conclusively delineate precipitation patterns. Myers (1964) encountered this problem in his study of radar echoes of central Pennsylvania. On the other hand, the radar operator can analyze what is being seen and correctly interpret the phenomena. This is done with respect to observations transmitted on teletype circuits. However, the concise description required for general use is not compatible with the quantitative detail needed for research.

In consideration of these factors, the data collection

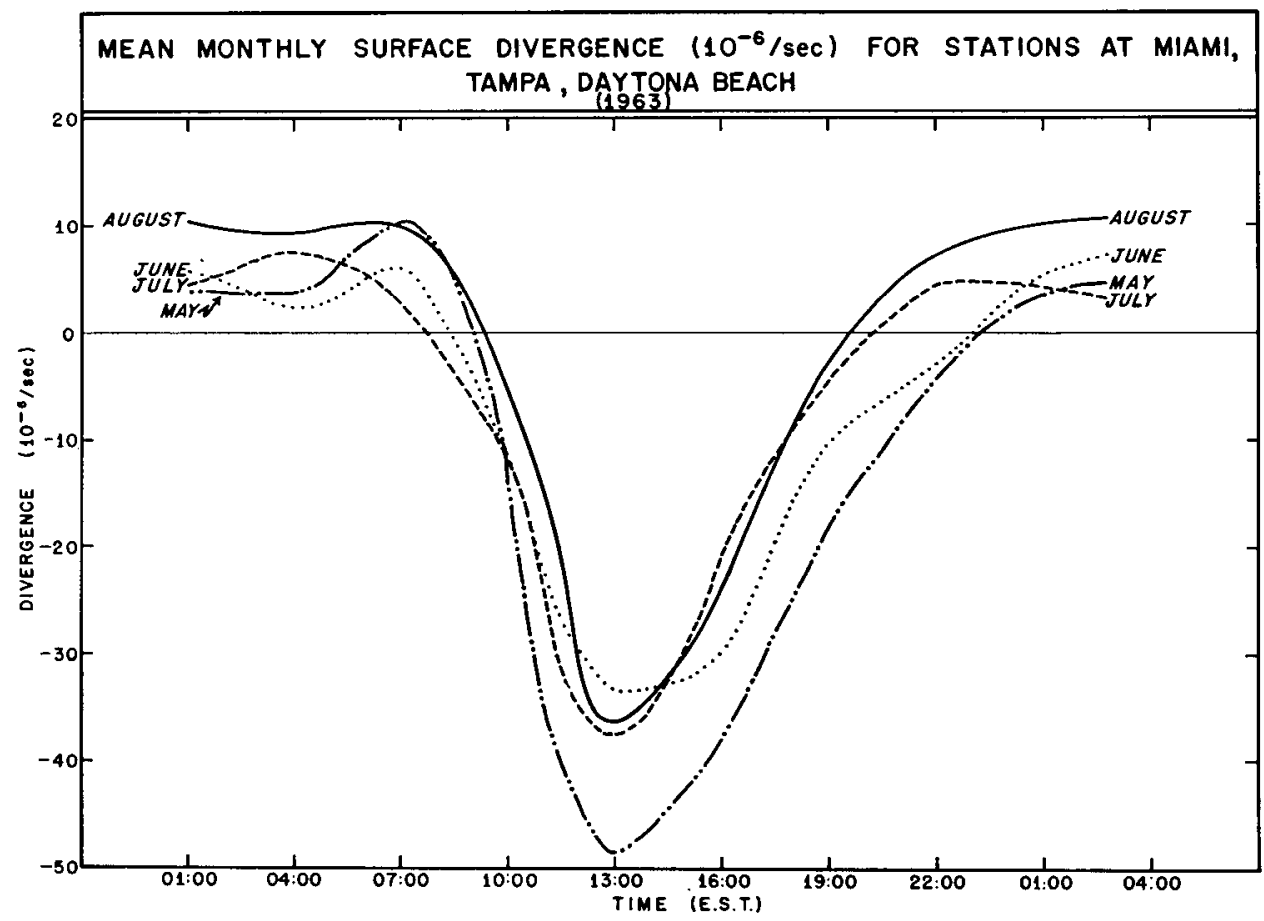

Frg. 1. The mean monthly diurnal surface divergence curves for the months May through August 1963 over the Florida peninsula. The divergence was computed by the Bellamy (1949) method using the triangle of stations, Miami, Tampa, and Daytona Beach. 
routine with the Miami WSR-57 radar was expanded to provide digital recording of echoes on a grid overlay during the summers of 1960 and 1961. Preliminary studies demonstrated the potential usefulness of the project and, beginning in 1962, it was extended to include observations from Tampa and Daytona Beach, providing coverage of the entire Florida peninsula and nearby waters. Data collected during the summer of 1963 have been processed. This note illustrates some of the results.

\section{Objectives}

The design of the project was based on the belief that the greatest practical application would be in revealing mesoscale patterns of shower activity. It was expected that temporal and spatial variations in con- vective activity could be correlated with such factors as the prevailing winds. Gentry and Moore (1954) found this to be true in a study for a small area near Miami using data from recording raingages. Radar provides a means of multiplying the number of observations and extending the field of view over both ocean and isolated interior areas.

It was felt that an examination of mesoscale features could be done most effectively in the absence of the masking influence of active weather producing systems of a synoptic scale. The project was therefore limited to the months May through August on the assumption that neither frontal nor tropical systems would present serious interference during this period. This conclusion is partially justified in Fig. 1 which shows the diurnal

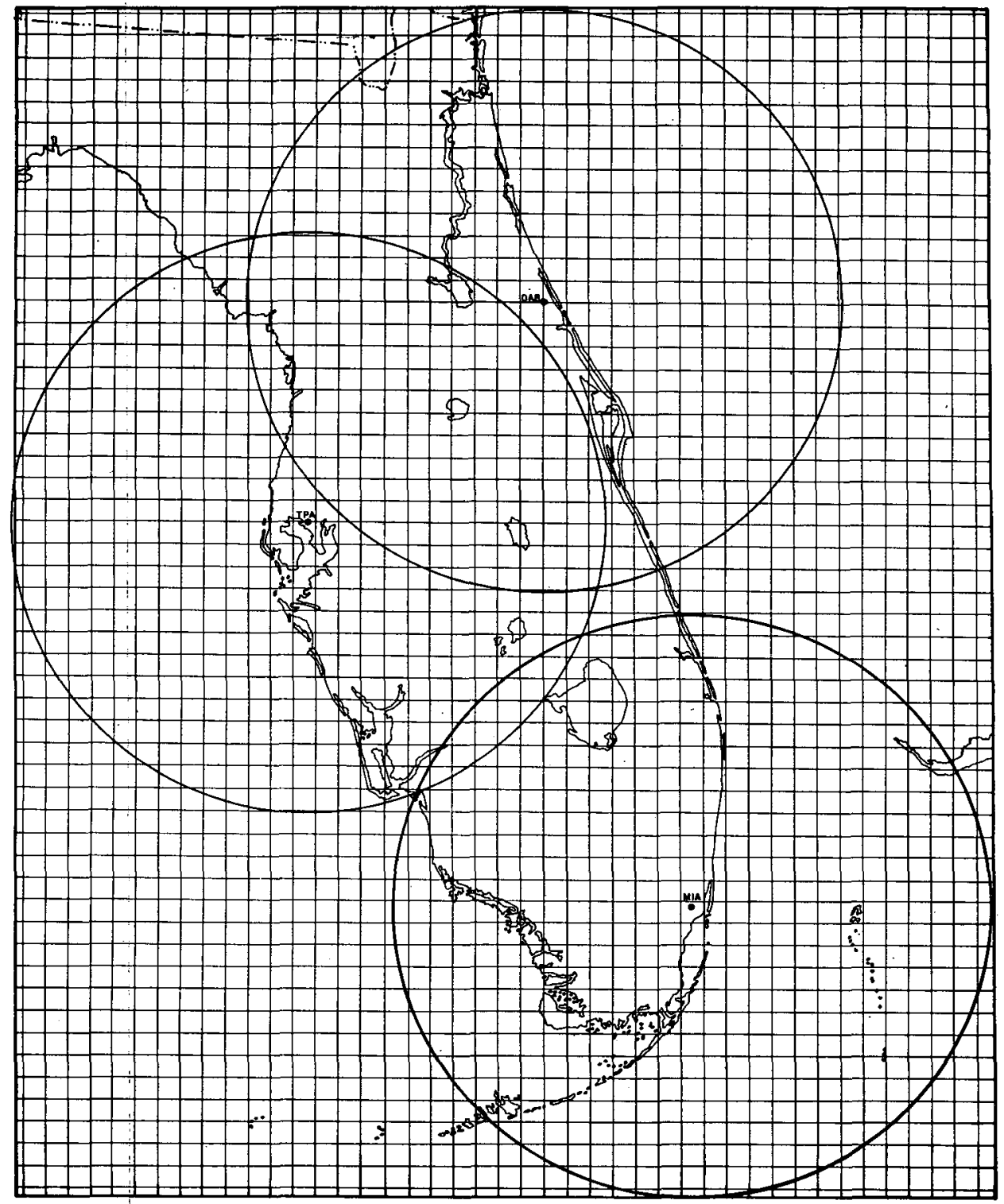

FIG. 2. The area covered by the three radar stations which participated in this study when the radar set was placed on a $100-\mathrm{mi}$ range. The 7.5 by $7.5 \mathrm{mi}$ grid has been superimposed on this figure. 
cycle of the mean monthly divergence values calculated from surface winds at Tampa, Daytona Beach, and Miami. The Bellamy triangle method (1949) was used to compute divergence. Obviously, local diurnal influences are dominant during this period. The maximum inflow is seen to occur at mid-day, while divergence reaches its highest value during the night. This is slightly at variance with results of the Thunderstorm Project (Byers and Braham, 1949) in which the lowlevel convergence maximum was found at 1600 local time. However, their conclusion was based on 6 -hr wind reports in contrast to the 3 -hr observations of the present study.

\section{Procedures in recording the data}

A range setting of $100 \mathrm{n}$ mi was chosen in order to avoid 1) failure to detect smaller cells which would not reach the level of the radar beam at greater distances, and 2) loss of resolution due to beam width at longer ranges. Fig. 2 shows the grid used and the coverage obtained by three radar stations. The grid interval is 7.5 $\mathrm{n}$ mi. At 3-hr intervals, the observers indicated by a check mark those grid squares showing precipitation echoes. Surface and 5000-ft winds were also recorded for possible use as predictors. The data were subsequently transferred to punch cards.

It has been assumed that precipitation was falling from most of the echoes observed. Considering the geographical location and season of the year, this is probably valid. Braham (1964) reported that 80 per cent of the convective echoes observed in southern Missouri produced measurable rain.

\section{Analysis of the data}

Since an important control of convective activity over Florida is the sea breeze, it is logical to examine the relationship of the radar echo distribution to this influence. The distance which the sea breeze penetrates inland and the associated vertical motion patterns are functions of the prevailing broad scale winds. Estoque (1962) illustrated this in a numerical model of the sea breeze. A preliminary study by Moore (1963), on a very limited sample, indicated fair agreement between radarobserved shower patterns and those implied by Estoque's calculations of the vertical motion. To test the hypothesis more completely, an approach similar to the one used by these two authors was employed.

Each day was placed into one of 5 regimes based on the 1200 GMT $5000-\mathrm{ft}$ winds. The 5000 -ft wind is assumed to represent the large-scale flow pattern. The 5 categories are defined in Fig. 3. The sector divisions are arbitrary and differ slightly for each station. Table 1 shows the number of days in each regime for the 3 stations.

In the first analysis the stations were treated separately. The diurnal cycle of shower activity was examined for the various regimes by computing echo fre-

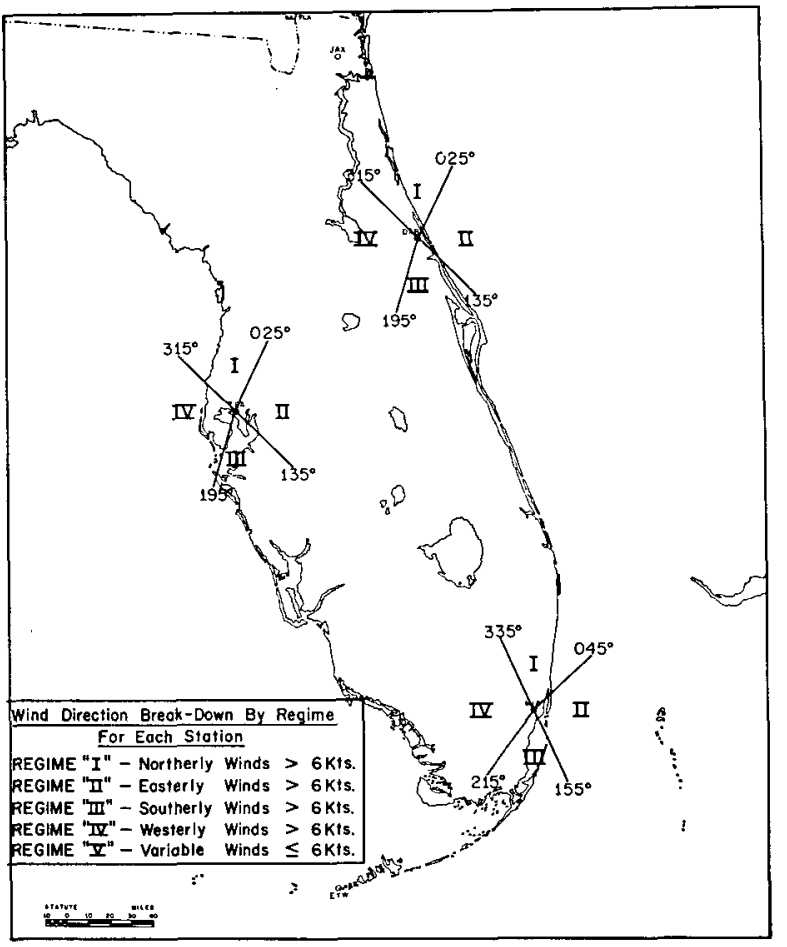

FIG. 3. The wind direction limits used to define each regine at the three radar stations.

quency maps for the 8 observations per day for 5 regimes. Space does not permit display of the complete file. A few of the more interesting features will be illustrated with selected maps for Miami.

The onset of the sea breeze develops a perturbation on the basic current which moves with the prevailing winds. This can be seen by comparing Figs. 4, 5 and 6 which show the 1000, 1300 and 1600 EST maps for the three regimes, onshore flow, offshore flow and the light and variable case. By 1000 the line of echoes which is apparently associated with the sea breeze has reached $15 \mathrm{mi}$ inland. The line is most prominent on the windward coast. As the day proceeds, the windward echo line (also referred to as the primary line in this paper) moves with the basic current and a secondary line forms on the opposite coast. This is best illustrated on the

\begin{tabular}{|c|c|c|c|}
\hline & Miami & Tampa & Daytona \\
\hline $\begin{array}{l}\text { Regime } 1 \text { : } \\
\text { (N'ly winds }>6 \mathrm{kt} \text { ) }\end{array}$ & 8 & 3 & 6 \\
\hline $\begin{array}{l}\text { Regime } 2 \text {. } \\
\quad\left(\mathbf{E}^{\prime} l y \text { winds }>6 \mathrm{kt}\right)\end{array}$ & 52 & 25 & 21 \\
\hline $\begin{array}{l}\text { Regime } 3 \text {. } \\
\quad \text { (S'ly winds }>6 \mathrm{kt} \text { ) }\end{array}$ & 8 & 21 & 18 \\
\hline $\begin{array}{l}\text { Regime } 4 . \\
\quad \text { (W'ly winds }>6 \mathrm{kt} \text { ) }\end{array}$ & 16 & 39 & 39 \\
\hline $\begin{array}{l}\text { Regime } 5 . \\
\text { (Light winds) }\end{array}$ & 31 & 32 & 31 \\
\hline
\end{tabular}



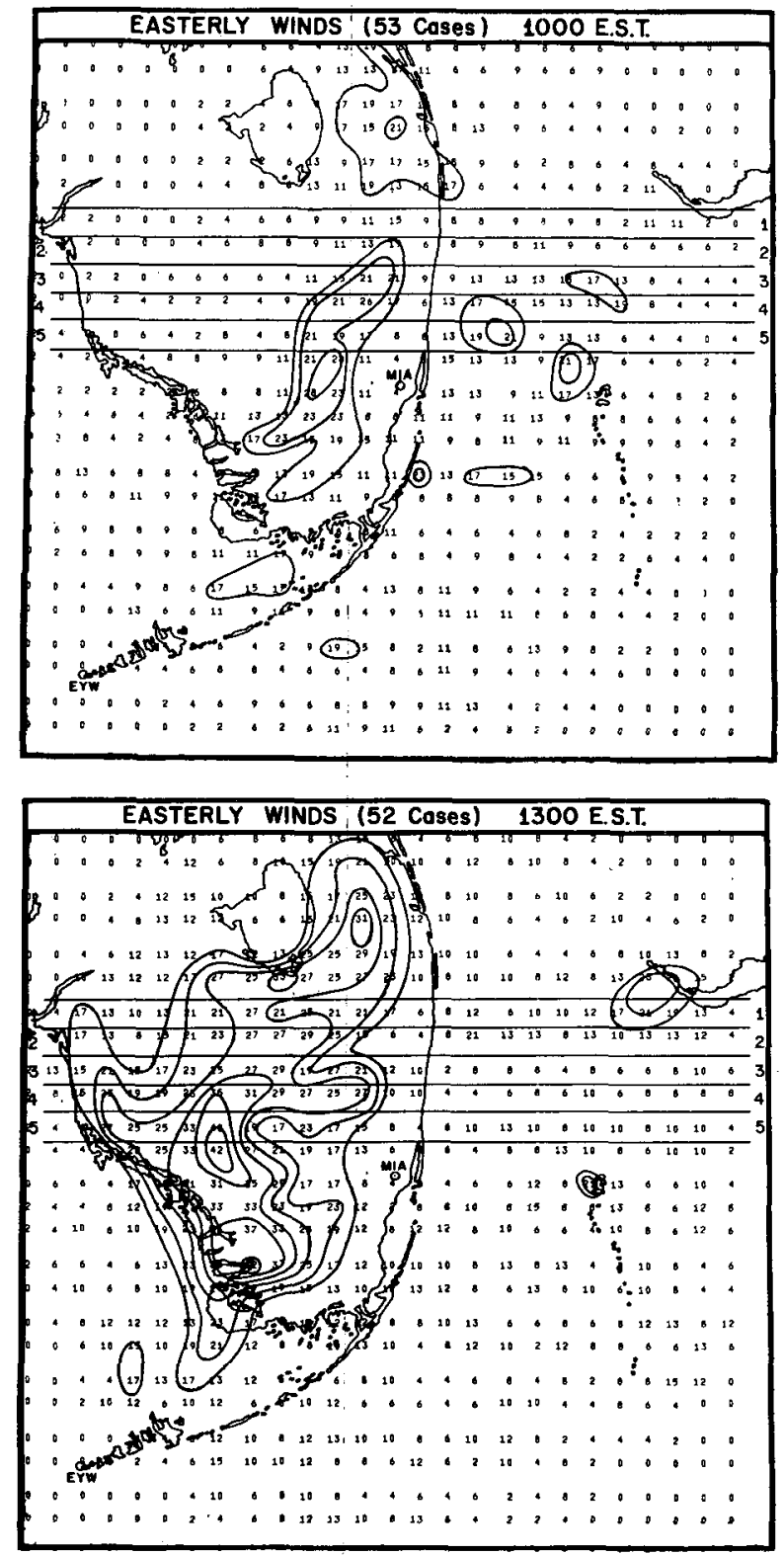

westerly regime chart for 1300 EST (Fig. 5b). By late afternoon, (Figs. $4 \mathrm{c}$ and $5 \mathrm{c}$ ), the primary and secondary lines tend to merge on the leeward coast. When the winds are light, the showers are equally prevalent on both coasts and show little movement during the day as illustrated in Fig. 6.

The limited data sample and other factors complicated the sea breeze pattern on the individual charts; therefore, a smoothing technique was used to highlight this feature. If it is assumed that temperature and surface friction differences between land and sea are the primary factors in determining the echo patterns, the bands should parallel the coast. Therefore, it was considered reasonable for the smoothing interval along the coast to be larger than the one in the perpendicular di-

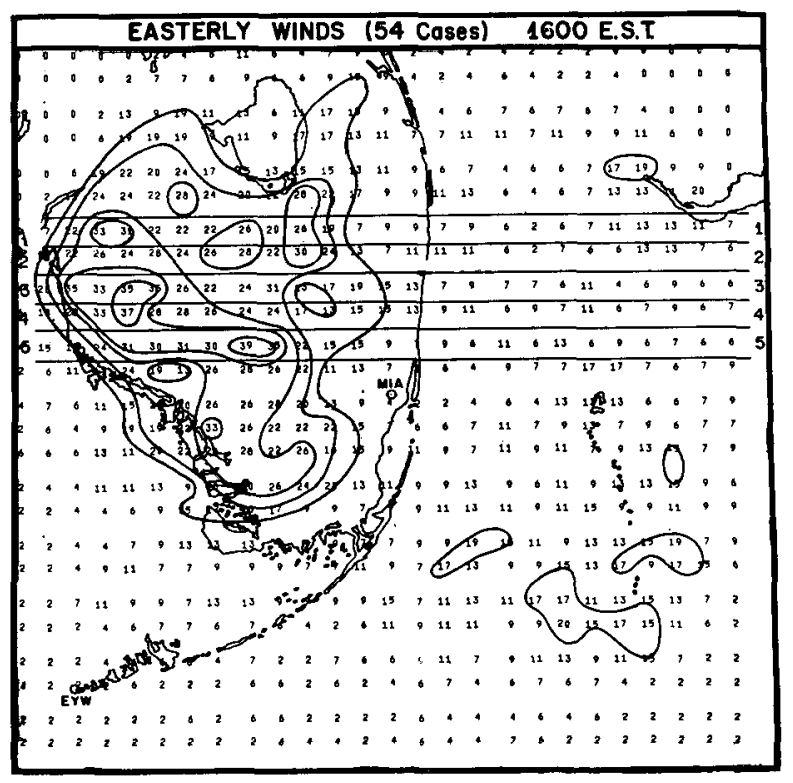

FIG. 4. The radar echo frequency (expressed in per cent) maps for the easterly regime at Miami for the times 1000,1300 and $1600 \mathrm{EST}$. Isolines of frequency are drawn in 5 per cent intervals beginning with the 15 per cent line. rection. Thus, the north/south medians of echo frequency were determined for the five grid rows shown in Figs. 4 through 6 . These median values were then smoothed in the east/west direction by a 3 grid (equal weight) running mean computation. Figs. 7 through 9 illustrate the diurnal cycle as shown by the resulting curves. To facilitate comparison, the 1600 frequency curves were extracted from Figs. 7 through 9 and combined in Fig. 10. The points mentioned above are much better illustrated on these diagrams. The progression of the windward shower axis along the basic current at a speed of $11 \mathrm{kt}$ and development near mid-day of a secondary maximum on the leeward coast can be seen in Figs. 7 and 8. Note also, in Fig. 10 at 1600, the maxi- 

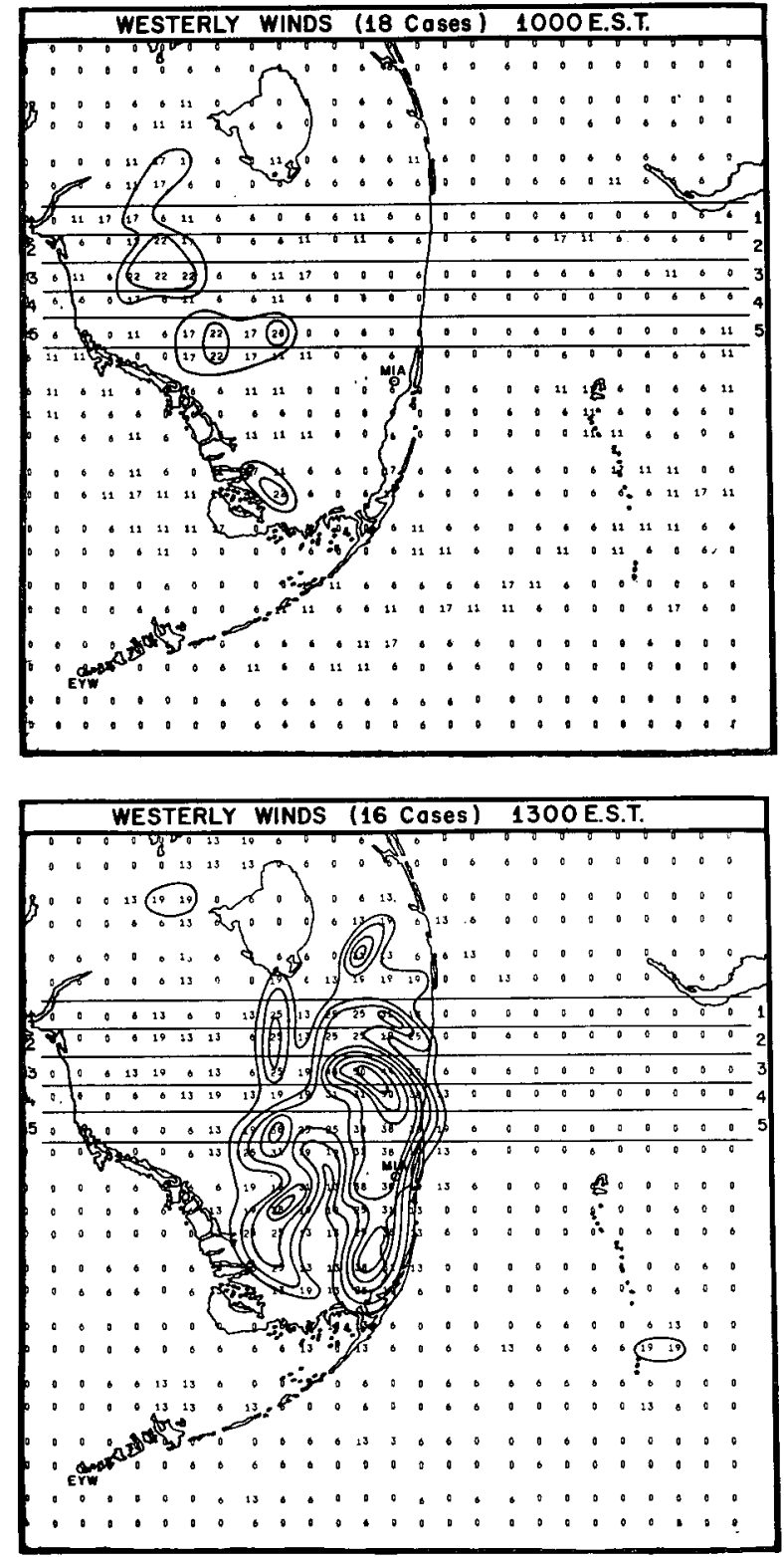

mum frequencies on the leeward coasts with a double maximum indicated for the light wind regimes.

The data from Daytona Beach and Tampa showed similar, but less marked patterns. The reason for this is unknown but is undoubtly related to terrain influences. The southern peninsula is flat with highest ground below $50 \mathrm{ft}$. From Lake Okeechobee northward low rolling hills of 100 to $300 \mathrm{ft}$ dominate and orographic effects are probably more pronounced.

Early morning coastal showers are also well related to the prevailing winds. Fig. 11 shows the 0700 EST smoothed frequency curves for the onshore and offshore regimes. The same smoothing technique was employed as described above. The east coast frequencies as well as location of the maximum axis with easterly

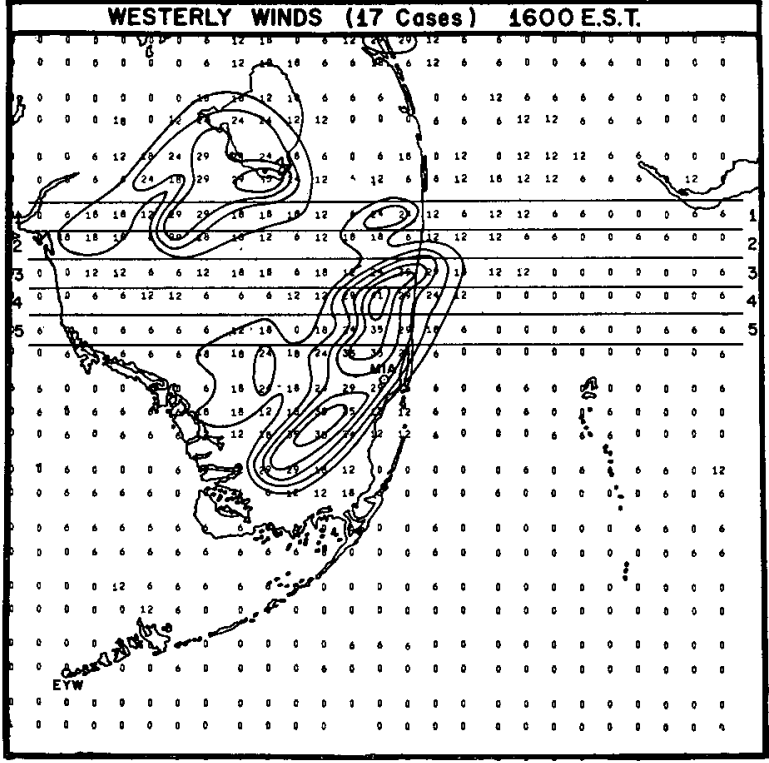

FIG. 5. Same as Fig. 4 except for the westerly regime.

flow are more pronounced and closer to the coast than with west winds. A similar pattern is also seen on the west coast; however, the frequencies are lower. It must be remembered we are viewing frequencies and not echo intensity. Morning showers tend to be weak and limited in vertical extent. The chances of being observed by radar are much better at closer ranges. The higher frequencies on the east coast are probably due to this effect.

\section{Climatology}

The simplest and most obvious use of the data collected is for determining seasonal averages or establishing a "climatology" of radar patterns. The project has not been underway long enough to ascertain the sta- 

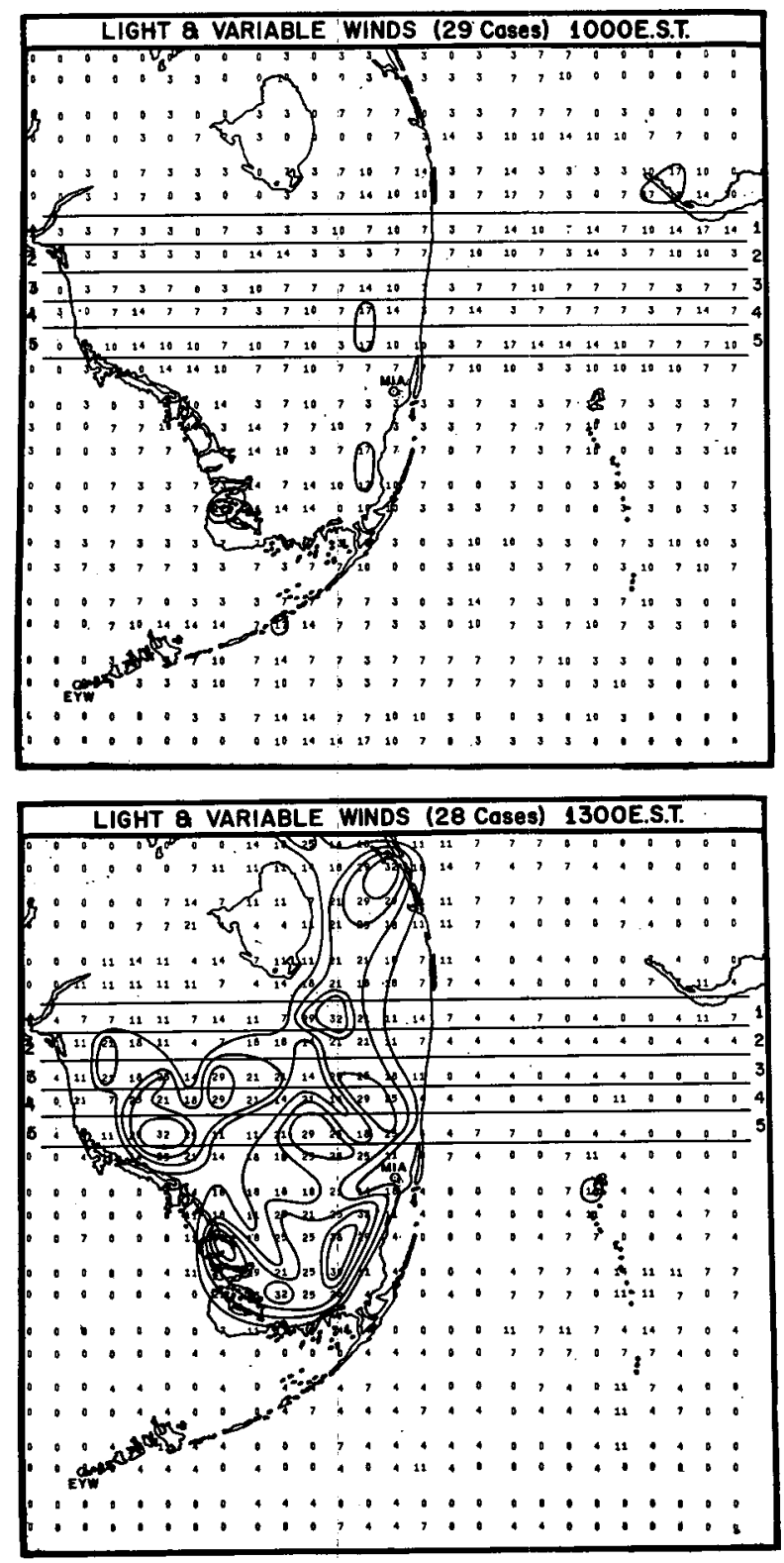

bility of the patterns but the 1963 seasonal distribution of echoes is of considerable interest.

Fig. 12 shows the diurnal cycle of radar echoes over the Florida peninsula from 0700 to 2200 for the summer seasons of 1963 (May-August). The nighttime maps for 0100 and 0400 are so similar to the 0700 chart that they are not shown. Isolines of echo frequency have been drawn for 5 per cent intervals starting with the 10 per cent line. The limit of the radar coverage for each station is included on the diagrams.

The dominant role played by solar heating is readily apparent as the radar echoes undergo a rhy thmic diurnal cycle. Over land, frequencies are highest in the late afternoon and lowest at night. As a matter of fact, frequencies over the peninsula from 2200-0700 EST are generally less than 10 per cent with large areas where

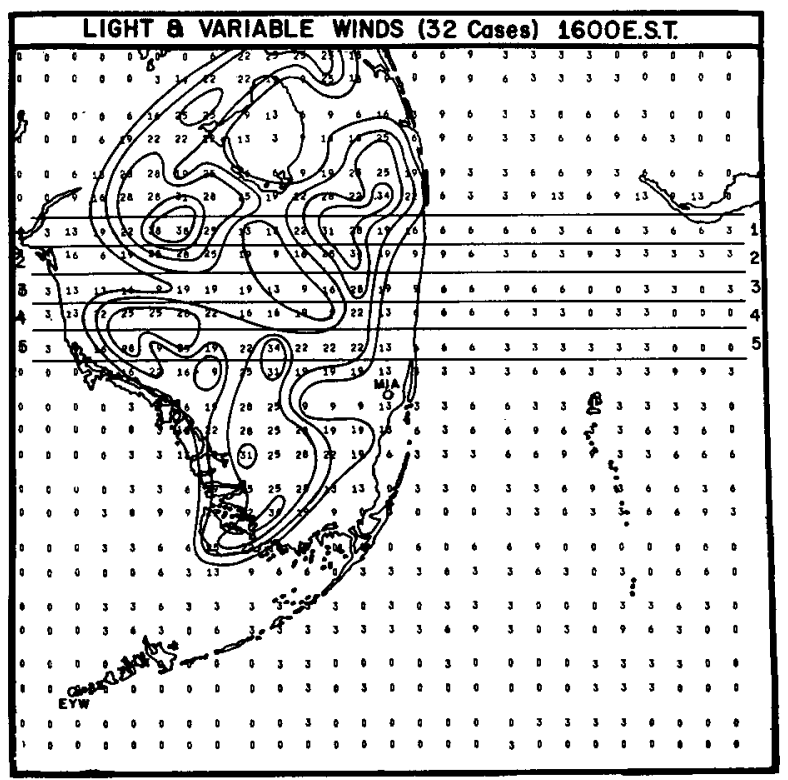

FIG. 6. Same as Fig. 4 except for the light and variable regime.

there were no echoes recorded at all. This lends support to the assumption made earlier that synpotic systems were at a minimum during this period.

Over the coastal waters, the reverse is true. Showers are more frequent at night. The 0700 chart shows the primary activity off the northwest and southeast coasts. This is undoubtly related to the prevailing wind. Table 1 shows that the easterly regime prevailed nearly half of the time in Miami. At Daytona and Tampa, westerly or light winds were more common. In the previous section it was shown that early morning coastal showers are more prevalent with onshore rather than offshore flow.

The spread or development of showers during the day generally follow the patterns shown for Miami. Over the 
southern half of the peninsula, the influence of prevailing easterlies is evident with late afternoon activity favoring the leeward (west) coast. North of Lake Okeechobee, the distribution is similar to some combination of the westerly and light wind categories with the latter regime being dominant. This is indicated by a tendency for a double maximum during the afternoon, one just west of Daytona Beach and the other inland from the west coast.

It is interesting to note the minimum of echoes over Lake Okeechobee particularly during the daytime. This feature has been observed by pilots for years and more recently the absence of clouds has also been seen on satellite pictures. Undoubtly this is caused by a weak lake breeze.

\section{Conclusions}

The purpose of this paper is to illustrate some of the features of mesoscale convection patterns which are not susceptible to treatment using conventional rainfall data over and near the Florida peninsula, and to demonstrate the value of a radar data collection program such as the one described. Ultimately, automatic digital recorders may serve this purpose. Atlas (1963) and Lhermitte

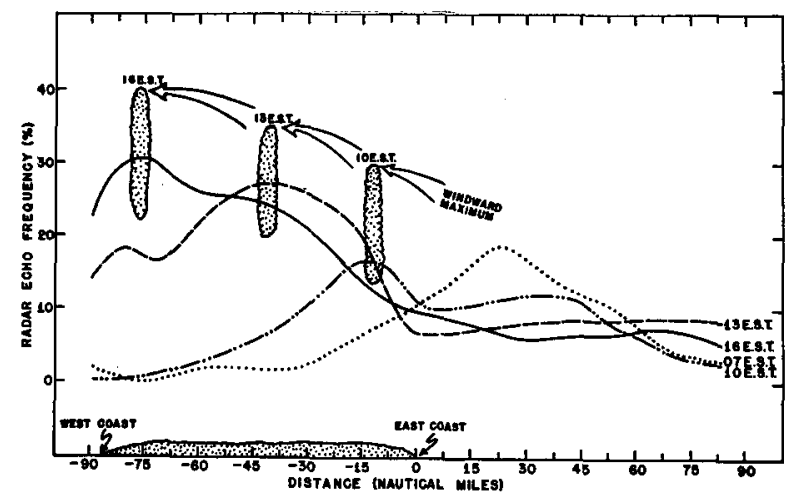

Frg. 7. Smoothed echo frequencies for five rows of data between Miami and Lake Okeechobee for the easterly regime.

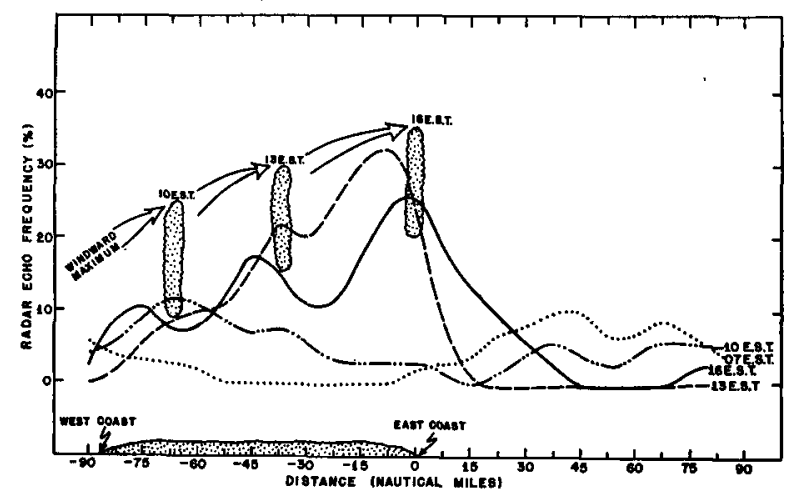

FIG. 8. Same as Fig. 7 except for westerly regime. and Kessler (1965) have discussed two approaches. However, it is not necessary to await the availability of such equipment to begin establishing a climatology of radar echoes and to employ such data for research in sub-synoptic scale forecasting. The latter will serve to narrow the gap between numerical prediction of largerscale features and the local weather distribution.

The present study was based on a limited data sample. Information collected subsequent to 1963 is being processed and the larger sample will permit more meaningful stratification and analysis. In addition, for

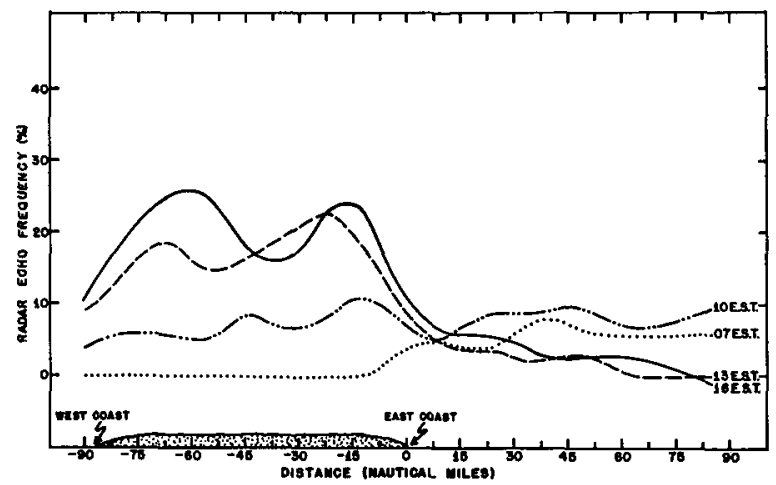

Fig. 9. Same as Fig. 7 except for the light and variable regine.

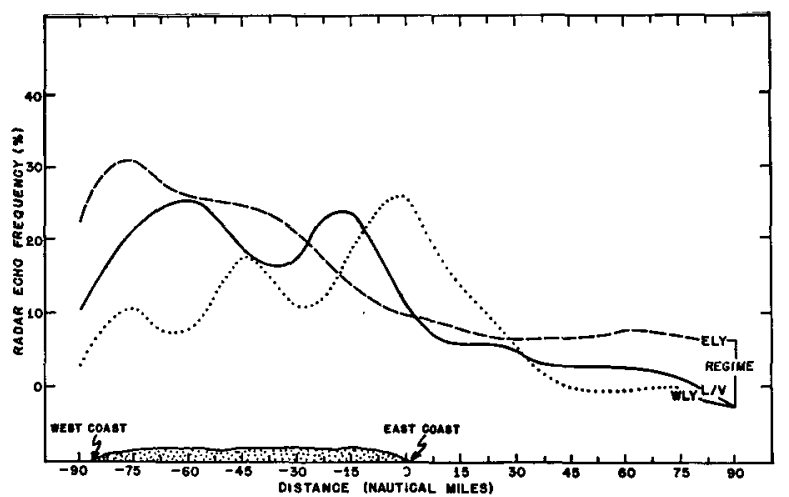

FIG. 10. Same as Fig. 7 except for 1600 EST.

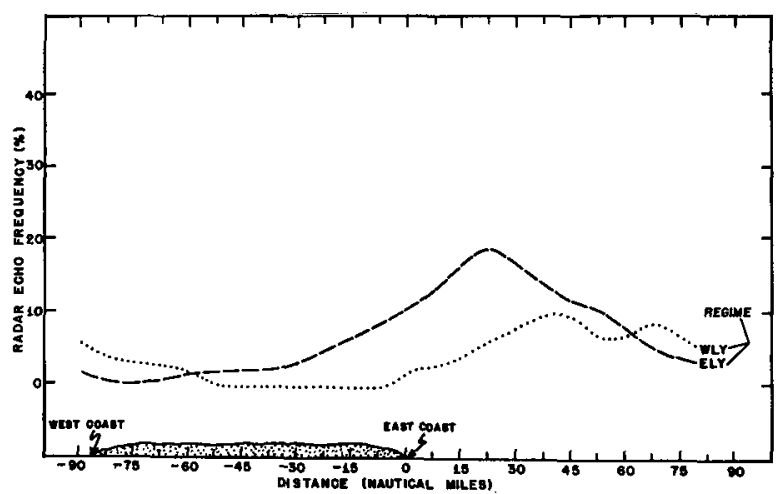

FIG. 11. Same as Fig. 7 except for 0700 EST. 

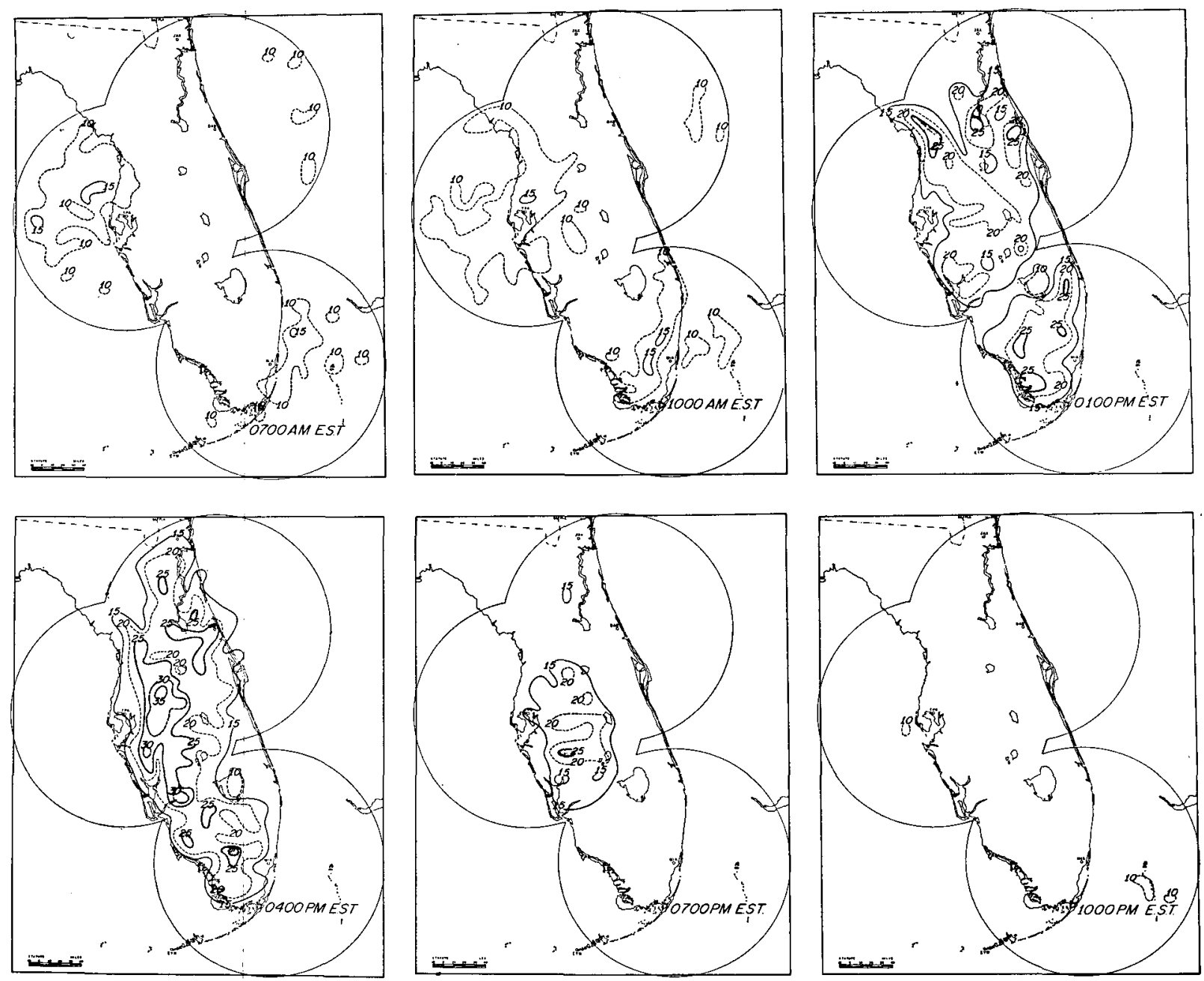

FIG. 12. The seasonal diturnal cycle of echo frequencies over the Florida peninsula for the months May through August 1963 excluding the 0100 and 0400 charts. Frequency isolines have been drawn in 5 per cent intervals beginning with the 10 per cent line.

summers of 1965 and 1966, the program was expanded to include data collection at Apalachicola, Fla., and Charleston, S. C.

Acknowledgments. The authors are indebted to Dr. R. C. Gentry, Director of the National Hurricane Research Laboratory for providing the computer time necessary to make these calculations. We are also deeply appreciative of all the radar observers at Tampa, Daytona, and Miami who faithfully recorded the observations that made this study possible.

\section{REFERENCES}

Atlas, D., 1963: Storm radar data processor observes a tornado. Bull. Amer. Meteor. Soc., 44, 44-45.

Bellamy, J. C., 1949: Objective calculations of divergence, vertical velocity and vorticity. Bull. Amer. Meteor. Soc., 30, 45-49.
Braham, R. R., 1964: What is the role of ice in summer rainshowers? J. Meteor., 21, 640-645.

Byers, H. R., and R. R. Braham, 1949: The Thunderstorm. U. S. Government Printing Office, Washington, D. C., $287 \mathrm{pp}$.

Estoque, M. A., 1962: The sea breeze as a function of the prevailing synoptic situation. J. Meteor., 19, 244-250.

Gentry, R. C., and P. L. Moore, 1954: Relation of local and general wind interactions near the sea coast to time and location of air-mass showers. J. Meteor., 11, 507-511.

Lhermitte, R. M., and Edwin Kessler, 1965: A weather radar signal integrator. Technical Memorandum No. 2. U. S. Department of Commerce, National Severe Storms Laboratory, Norman, Okla., 7 pp.

Moore, P. L., 1963: A radar study of shower activity associated with the sea breeze. Proc. Tenth Weather Radar Conf., Boston, Amer. Meteor. Soc., 8-12.

Myers, J. N., 1964: Preliminary radar climatology of central Pennsylvania. J. Appl. Meteor., 3, 421-429. 